\title{
Aedes aegypti abundance, larval indices and risk for dengue virus transmission in Kinondoni district, Tanzania
}

\author{
Baraka L. Ngingo $0^{1,2,3^{*}} \mathbb{D}$, Leonard E. G. Mboera², Augustino Chengula', Ines Machelle ${ }^{1,2}$, Mariam R. Makange ${ }^{1,2}$, \\ Michael Msolla1,2, Gaspary O. Mwanyika ${ }^{1,2,4}$, Sima Rugarabamu1,2,5 and Gerald Misinzo 1,2
}

\begin{abstract}
Background: Tanzania has experienced periodic dengue outbreaks with increased incidence since 2010. However, there is limited information on vector dynamics and transmission risk in most parts of the country. This study was conducted to determine Aedes mosquito abundance, larval indices and dengue virus infection rate as risk indicators for DENV transmission in Kinondoni district, Dar es Salaam, Tanzania.

Methods: A cross-sectional study was conducted in three wards of Kinondoni district in Tanzania between December 2019 and January 2020. In each ward, three streets were randomly selected for adult and immature mosquito sampling. The adult mosquitoes were collected using Mosquito Magnet traps, while mosquito larvae and pupae were inspected in water-holding containers in the selected household compounds. The detection of dengue virus (DENV) in female Aedes mosquitoes was done using a one-step reverse transcription-polymerase chain reaction (RT-PCR) method.

Results: Of the 1416 adult female mosquitoes collected, Ae. aegypti accounted for $16.8 \%(n=238)$. A total of 333 water-holding containers were inspected and 201 (60.4\%) had at least an Aedes larvae or pupae. Water-holding containers supporting the breeding of Aedes larvae and pupae included discarded car tires, flowerpots and small and large plastic containers. The overall House Index, Container Index and Breteau Index were 55.1\%, 60.4\% and 114.2, respectively. None of the 763 female Aedes mosquitoes tested by RT-PCR was found to be infected with DENV.

Conclusion: The presence and abundance Ae. aegypti mosquitoes and the large proportion of water-holding containers infested with the mosquito larvae and pupae put residents of Kinondoni district at high risk of DENV transmission. Our findings emphasize the need for continuous mosquito vector surveillance and control to prevent the possibility of future DENV outbreaks in Tanzania.
\end{abstract}

Keywords: Dengue, Aedes aegypti, Productivity, Transmission risk, Tanzania

\section{Background}

Dengue is a mosquito-borne viral disease of global health concern. The disease has spread throughout the tropical and sub-tropical regions over the past 60 years

*Correspondence: baraka.ngingo@sacids.org

${ }^{1}$ Department of Veterinary Microbiology, Parasitology and Biotechnology, Sokoine University of Agriculture, Morogoro, Tanzania

Full list of author information is available at the end of the article and currently affects over half of the world's population [1]. The disease is caused by dengue virus (DENV), an RNA virus with four distinct serotypes, DENV1-4, each capable of causing disease, ranging from mild fever to severe disease [2]. The spread of DENV infection is driven by increased international travel, climate change effect associated with high humidity and temperature, and poor urban environmental conditions 
that favour mosquito survival, breeding, and abundance [3].

In Tanzania, dengue was first reported in the southern coastal district during the fifteenth Century by Spanish sailors [4-6]. Dengue outbreaks were later reported between 1823 and 1870 on the Islands of Zanzibar archipelago [7]. During the past 10 years, dengue outbreaks in Tanzania have been reported with increased incidence [8-10]. The most recent outbreak in 2019 affected mainly Dar es Salaam and Tanga cities, where a total of 6,917 confirmed cases and 13 deaths (case fatality rate of $0.19 \%$ ) were reported [11]. Moreover, seroprevalence studies have reported dengue in several regions of Tanzania with rates between $6.4 \%$ and $50.6 \%$ [8, 10, 12-16]. All the four DENV serotypes, DENV-1, DENV-2, DENV-3 and DENV-4 have been reported in Tanzania $[8,10,17,18]$. Despite of frequent dengue outbreaks in the country, no vector control measures have been introduced.

Dengue virus is transmitted between humans through a bite of an infected Aedes mosquito. The main vectors that are geographically widespread include $A e$. aegypti and Ae. albopictus [2]. Ae. aegypti is an extensive domestic day-biting species that prefer to feed on humans. It breeds in flower vases, uncovered barrels, buckets, discarded cans, roof gutters and discarded tires $[8,19]$ while Ae. albopictus, preferentially rests outdoors [20] and alternatively feeds on humans and animals, though it has been reported to exhibit strong anthropophagic behaviour in some countries [21]. In Tanzania, Ae. aegypti is the main vector of Dengue [8], no report on presence of Ae. albopictus. DENV infection rate of $2 \%$ [22] 8\% [8] in Ae. aegypti mosquitoes have been reported in Dar es Salaam. Relatively higher DENV infection rate of $47.6 \%$ in Ae. aegypti have been recorded in a study in Kagera, Mwanza, Morogoro and Mbeya regions [23]. Nevertheless, the extents of viral infections in vector mosquitoes in other parts of the country have not been well established. Screening for DENV serotypes in mosquitoes will give baseline data for future vector control intervention studies.

Though several dengue outbreaks have been reported in Tanzania during the past decade, information on mosquito vectors and transmission indices are limited. So far, five entomological surveys have been reported; of which only three have established transmission levels of DENV [8, 22, 23]. This study was, therefore, carried out to determine Aedes mosquito abundance, larval indices and dengue virus infection rate as risk indicators for DENV transmission in Kinondoni district, Dar es Salaam, Tanzania.

\section{Methods}

\section{Study area and design}

This cross-sectional entomological study was carried out in Kinondoni district of Dar es Salaam City in eastern Tanzania between December 2019 and January 2020. The district has a total area of $531 \mathrm{~km}^{2}$ with a population of about 1,775,049 and a population density of 3343 inhabitants per $\mathrm{km}^{2}$ [24]. The climate is generally hot and humid, with small seasonal and daily variations in temperature. The mean annual temperature and the annual rainfall are about $30{ }^{\circ} \mathrm{C}$ and $1100 \mathrm{~mm}$, respectively. The relative humidity is generally high and ranges between 65 and $96 \%$ in a year [25]. Kinondoni district was selected purposely, because the district has experienced periodic dengue outbreaks since 2014 [8, 10, 16].

Mosquito sampling was conducted in Mikocheni, Mzimuni, and Mwananyamala wards selected based on ecological and demographical characteristics. Mikocheni is a high-income area characterized by sparsely populated neighbourhood (low population density). Sampling streets have regular blocks with high standard dwellings, high vegetation coverage, piped water supply and regular garbage collection. The houses generally have large and shaded peridomestic environments, while Mwananyamala is a low-income area characterized by unplanned urbanization and high population density. Sampling streets were characterized by low vegetation coverage, insufficient piped water supply and irregular waste collection. Mzimuni is a low to middle-income area characterized by unplanned urbanization and high population density. Sampling streets were characterized by low vegetation coverage, insufficient piped water supply and irregular waste collection. In each ward, three streets were randomly selected as sampling points making a total of nine study streets, namely, Regent Estate, Mikocheni A, TPDC, Idrisa, Mwinyimkuu, Mtambani, Msisiri A, Msisiri B and Kopa (Fig. 1).

\section{Mosquito sampling and breeding habitat assessment}

This study involved sampling of both adult and immature stages of mosquitoes. The sampling procedure used for collecting adult mosquitoes is as described by Mboera et al. [8]. Adult mosquitoes were collected using carbon dioxide-propane powered Mosquito Magnet Liberty Plus traps (American Biophysics Corporation, Rhode Island, USA), fixed at nine sentinel sites (three sites in each sampling ward). A total of nine traps were set, three in each of the three study wards of Kinondoni district and allowed to operate for 3 days consecutively. The traps were set in the morning and operated throughout the day and night. The mosquito catches were collected the following day between 6:00 a.m. and 08:00 a.m., identified 


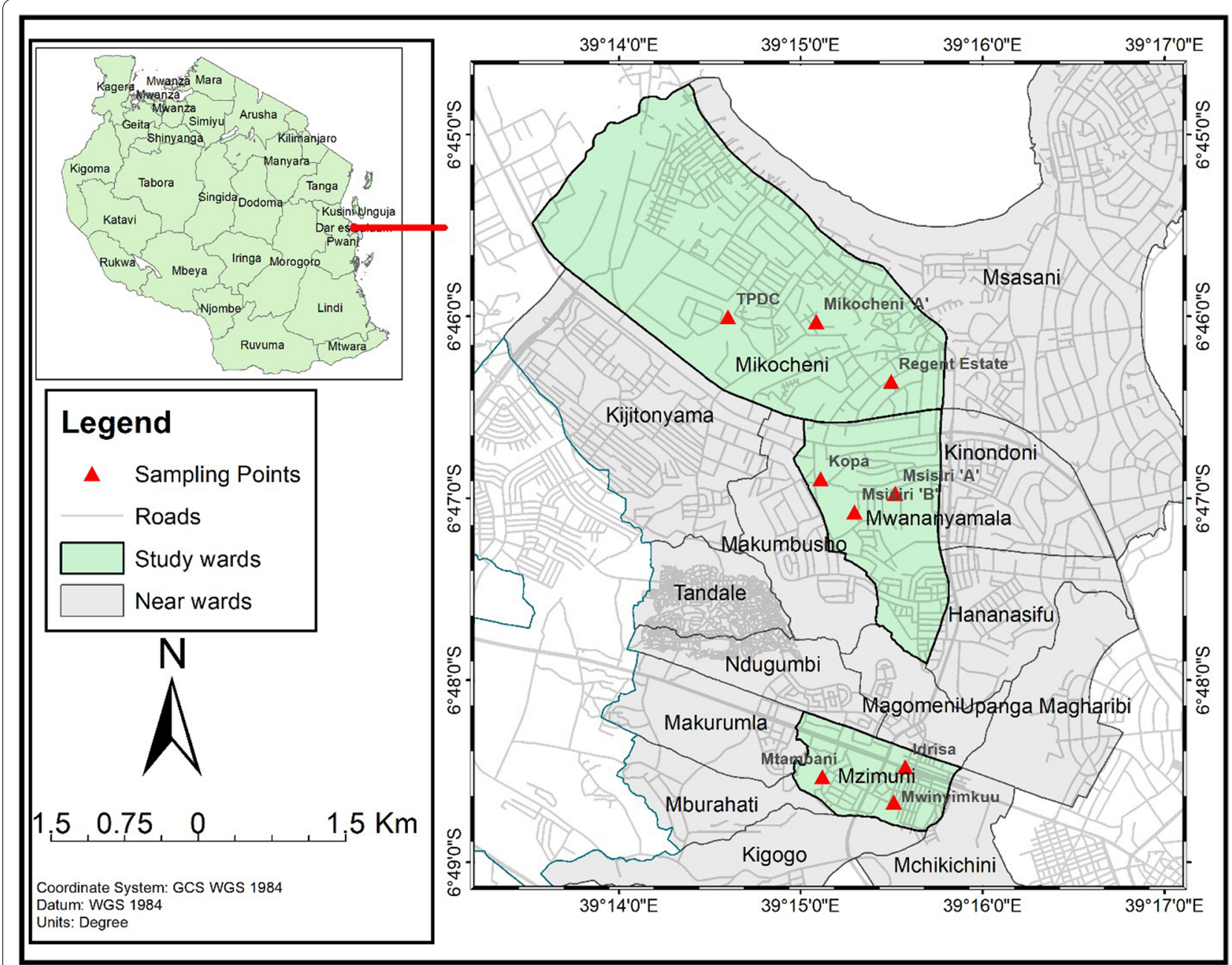

Fig. 1 Map of Kinondoni district showing the study wards and sampling sites (in red triangles). The map was developed using ArcGIS software version 10.5 (Esri, CA, USA)

morphologically and stored for further analysis. A manual aspirator was used to correct the mosquitoes from the traps [26].

In all streets visited, there was a register book with house number and names of the household owner. All house numbers were taken and sampling frame were prepared in MS Excel. Random numbers were generated for selection of houses for this study. The number of households to be involved was determined as described previously [27]. The operational guide for assessing the productivity of Ae aegypti breeding sites was according to the guidelines by the World Health Organization [28].Twenty randomly selected households in each of the study streets were visited and inspected for the presence of water-holding containers [27]. All areas surrounding the selected household compound were visited and inspected for the presence of water holding containers.
The larval search team consisted of five research assistants all visiting and inspecting one house after the other. This was to make sure that all potential water holding containers are thoroughly searched for presence of immature stages of mosquitoes. All water-holding containers found were examined for the presence of mosquito larvae and pupae. A container found with a larva or pupa was considered positive for the presence of immature mosquito stages. Larvae and pupae found were collected into a small bowl using standard plastic dippers and transferred using Pasteur pipette into a labelled waterfilled Whirl-Pak plastic bag (Thomas Scientific, Swedesboro, USA). The collected larvae and pupae were taken in a cool box to an insectary at the Muhimbili University of Health and Allied Sciences in Dar es Salaam for rearing. In the insectary, the larvae were fed on Whiskas ${ }^{\circledR}$ cat food and maintained at $26 \pm 2{ }^{\circ} \mathrm{C}$ and relative humidity 
of $82 \pm 10 \%$. Pupae were collected by trained staff each morning and evening and transferred to pupae emergence cups in netting cages and left until adults emerged. Upon emergence, adult mosquitoes were euthanized at $-20{ }^{\circ} \mathrm{C}$ for $15 \mathrm{~min}$ and identified morphologically to the species level with the aid of a stereo-microscope [26].

\section{Mosquito processing}

Twenty females Ae. aegypti were pooled into welllabelled $1.5 \mathrm{~mL}$ cryovial tubes according to the collection site and whether captured or reared and then frozen in liquid nitrogen $\left(-196^{\circ} \mathrm{C}\right)$. The mosquito specimens were transported to the Sokoine University of Agriculture Laboratory in Morogoro, Tanzania. In the laboratory, the pooled specimens were placed in a $1.5 \mathrm{~mL}$ microcentrifuge tube with $500 \mu \mathrm{L}$ of Dulbecco's Modified Eagle Medium (Sigma-Aldrich Chemie $\mathrm{GmbH}$, Taufkirchen, Germany), ground and centrifuged at $12,000 \mathrm{rpm}$ for $1 \mathrm{~min}$ and $200 \mu \mathrm{L}$ of the supernatant was stored at $-80^{\circ} \mathrm{C}$ until analysed.

\section{Screening of DENV}

Viral ribonucleic acid (RNA) was extracted from each pool of mosquitoes using QIAamp Viral RNA Kit (Qiagen, Hilden, Germany), according to the manufacturer's instructions. RNA was eluted in $60 \mu \mathrm{L}$ of elution buffer provided with the kit. The eluted RNA was aliquoted into three aliquots of $20 \mu \mathrm{L}$ each and immediately stored at $-20{ }^{\circ} \mathrm{C}$ until analysed. The quality and quantity of RNA was evaluated using the NanoDrop ND1000 spectrophotometer (Biochrom LTD, Cambridge, England). One-step reverse transcription-polymerase chain reaction (RTPCR) was done using SuperScript III Platinum/Taq DNA polymerase kit (Invitrogen, Carlsbad, CA, USA) according to the manufacturer's instructions using D1 and D2 primers that amplify a $511 \mathrm{bp}$ fragment of the polyprotein gene at 134 and 644 genomic position [29].

Reverse transcription-polymerase chain reaction was carried out in a $25 \mu \mathrm{L}$ reaction containing $12.5 \mu \mathrm{L}$ of $2 \times$ reaction mix, $1 \mu \mathrm{L}$ of SuperScript III RT/Platinum Taq mix, $0.5 \mu \mathrm{L}$ of $10 \mu \mathrm{M}$ sense primer (D1), $0.5 \mu \mathrm{L}$ of $10 \mu \mathrm{M}$ anti-sense primer (D2), $0.5 \mu \mathrm{L}$ Magnesium sulphate (Invitrogen, CA, USA), $4 \mu \mathrm{L}$ of RNA template and 6 $\mu \mathrm{L}$ of nuclease-free water. Reverse-transcription reaction was performed in $1 \mathrm{cycle}$ at $48^{\circ} \mathrm{C}$ for $30 \mathrm{~min}$, followed by one cycle of initial denaturation at $94^{\circ} \mathrm{C}$ for $2 \mathrm{~min}$. Thermocycling conditions were 35 cycles of denaturation at $94{ }^{\circ} \mathrm{C}$ for $15 \mathrm{~s}$, annealing at $55^{\circ} \mathrm{C}$ for $30 \mathrm{~s}$, and elongation at $68^{\circ} \mathrm{C}$ for $1 \mathrm{~min}$ and a final extension at $68^{\circ} \mathrm{C}$ for $5 \mathrm{~min}$. The PCR amplicons were separated on $1.5 \%$ agarose gel electrophoresis and visualized using Gel doc EZ Imager System (Bio-Rad Laboratories, Hercules, CA, USA).

\section{Data analysis}

Data were entered into Microsoft Excel sheet 2016 (Microsoft Corporation, Washington, USA), cleaned and evaluated against data collection forms. The proportion of mosquitoes by species and wards, households with water holding container were calculated and presented in tables. Risk for DENV transmission was assessed using dengue risk indicators, including Aedes mosquito abundance, larval indices and dengue virus infection rate. The level of Aedes mosquito infestation and dengue transmission levels were assessed by: (i) House index as the percentage of houses infested with larvae and/or pupae; (ii) Container index as the percentage of water-holding containers infested with larvae and/or pupae; and (iii) Breteau index as the number of positive containers per 100 houses inspected in a specific location. From these indices, potential risk of dengue transmission was estimated based on the World Health Organization criteria, which states that where the $\mathrm{BI}, \mathrm{HI}$ and $\mathrm{CI}$ exceeded 50, 35 and 20, respectively, the risk of dengue transmission is considered high. Where the $\mathrm{BI}$ is between 5 and 50, the density of $A e$. aegypti was considered sufficient to promote an outbreak of Dengue. Where the BI was less than 5 , the HI less than 4 , and the CI was also less than 3 , it is considered unlikely for transmission of dengue to occur [30].

Chi-square and $t$ test were used to test for significant differences in indices and mosquito female $A e$. aegypti abundance between study wards, respectively. All the results with $\mathrm{p}<0.05$ were considered statistically significant.

\section{Results \\ Mosquito species composition and abundance}

A total of 1,416 adult female mosquitoes were collected outdoors using Mosquito Magnet traps. Culex quinquefasciatus was the most abundant mosquito species accounting for $52.3 \%(n=740)$ of the total female mosquitoes collected. Mansonia species and Ae. aegypti accounted for $30.9 \%(n=438)$ and $16.8 \%$ $(n=238)$, respectively. A statistically significant variation in female Ae. aegypti abundance between study wards was observed $(p<0.05)$. The largest proportion of Ae. aegypti mosquitoes were collected from Mikocheni (Table 1). A total of 1,750 Ae. aegypti mosquitoes hatched from the larvae and pupae reared in the insectary (Table 2). $30 \%$ of the female Ae. aegypti mosquitoes hatched in the respective sampling ward were randomly selected and packed for detection of DENV virus. 
Table 1 Number and percentage of adult mosquitoes collected by ward and species

\begin{tabular}{llll}
\hline Ward & Species & No & Percentage \\
\hline Mikocheni & Aedes aegypti & 148 & 42.4 \\
& Culex quinquefasciatus & 201 & 57.6 \\
\multirow{4}{*}{ Mwananyamala } & Subtotal & 349 & 24.6 \\
& Aedes aegypti & 36 & 4.0 \\
& Culex quinquefasciatus & 436 & 47.9 \\
& Mansonia spp. & 438 & 48.1 \\
\multirow{4}{*}{ Mzimuni } & Subtotal & 910 & 64.3 \\
& Aedes aegypti & 54 & 34.4 \\
& Culex quinquefasciatus & 103 & 65.6 \\
& Subtotal & 157 & 11.1 \\
& Total & 1416 &
\end{tabular}

Table 2 Number of hatched mosquitoes by sampling location

\begin{tabular}{lll}
\hline Ward & $\begin{array}{l}\text { Total Ae. aegypti } \\
\text { corrected }\end{array}$ & $\begin{array}{l}\text { No of Ae. aegypti } \\
\text { screened for } \\
\text { DENV }\end{array}$ \\
\hline Mikocheni & 876 & 263 \\
Mwananyamala & 328 & 98 \\
Mzimuni & 546 & 164 \\
Total & 1750 & 525 \\
\hline
\end{tabular}

\section{Mosquito breeding sites and Aedes indices}

A total of 176 houses were inspected for the presence of immature stages of Aedes mosquito. Of these, 132 (75\%) houses had water-holding containers in their premises. Mikocheni had the largest proportion $(85 \%)$ of households with water-holding containers, followed by Mzimuni (75.9\%) and Mwananyamala (63.8\%). About two-thirds $(60.4 \%)$ of the household premises had at least a container with mosquito larvae or pupae. A total of 333 outdoor containers were found and inspected for the presence of Ae aegypti larvae or pupae (Table 3). Of 109 discarded car tires inspected, 94 (80.2\%) were infested with Ae. aegypti immature stages. Other water holding containers infested with Aedes larvae/pupae were small plastic containers, flower pots, water buckets, unused fish pond and water drums (Table 3). Discarded car tires accounted for the largest proportion (76\%) of water-holding containers harbouring pupae. About two-thirds (60\%) of the flower pots and cement water tanks were also infested with pupae (Table 3).

The overall Aedes house index (HI) was 55.1\%. The highest HI (71.7\%) was found in Mikocheni, followed by Mwananyamala (48.3\%) and Mzimuni (44.8\%). There was a significance difference in House indices between wards $(x=54.93,95 \%$ CI: $18.6-91.2 \pm 14.6, p=0.023)$. The overall container index (CI) was $60.4 \%$, with Mikocheni having significantly the higher CI (73.2\%) than Mwananyamala $(56.8 \%)$ and Mzimuni $(50.4 \%)(x=60.13$, 95\% CI: $30.9-89.3 \pm 11.8, p=0.013)$. The overall Breteau index was 114.2, with the highest value found in Mikocheni (150), followed by Mzimuni (112.1) and Mwananyamala (79.3). The difference in Breteau indices between wards was statistically significant $\left(x^{-}=113.8,95 \%\right.$ CI: $25.9-$ $202.0 \pm 35.4, p=0.031$ ) (Fig. 2).

\section{Dengue virus detection}

Overall, 51 pools consisting of 763 (238 trapped and 525 hatched) females Ae. aegypti were tested for DENV infection using one-step RT-PCR. Of these, 22 pools were from field trapped adult mosquitoes and 29 pools were

Table 3 Type and number of water-holding containers infested with mosquito larvae or pupae

\begin{tabular}{|c|c|c|c|c|c|c|c|c|}
\hline \multirow[t]{3}{*}{ Type of container } & \multicolumn{8}{|c|}{ Number of containers (containers infested with pupae) } \\
\hline & \multicolumn{2}{|c|}{ Mikocheni } & \multicolumn{2}{|c|}{ Mwananyamala } & \multicolumn{2}{|l|}{ Mzimuni } & \multicolumn{2}{|l|}{ Total } \\
\hline & Larvae & Pupae & Larvae & Pupae & Larvae & Pupae & Larvae & Pupae \\
\hline Cement water tank (1000 L) & $3(2)$ & $3(1)$ & $1(1)$ & $1(1)$ & $1(1)$ & $1(1)$ & $5(4)$ & $5(4)$ \\
\hline Flower pot & $11(7)$ & $11(3)$ & $4(3)$ & $4(3)$ & $6(6)$ & $6(6)$ & $21(16)$ & $21(12)$ \\
\hline Plastic container (5-20 L) & $5(3)$ & $5(2)$ & $2(0)$ & $2(0)$ & $10(3)$ & $10(2)$ & $17(6)$ & $17(4)$ \\
\hline Plastic water drum (200 L) & $3(2)$ & $3(1)$ & $4(3)$ & $4(3)$ & $3(1)$ & $3(1)$ & $10(6)$ & $10(5)$ \\
\hline Water tank (> 200 L) & $7(7)$ & $7(5)$ & $4(2)$ & $4(2)$ & $4(0)$ & $4(0)$ & $15(9)$ & $15(7)$ \\
\hline Discarded car tires & $45(38)$ & $45(27)$ & $19(18)$ & $19(18)$ & $45(38)$ & $45(38)$ & $109(94)$ & $109(83)$ \\
\hline Plastic container $(<5 \mathrm{~L})$ & $4(4)$ & $4(1)$ & $5(4)$ & $5(4)$ & $6(4)$ & $6(3)$ & $15(12)$ & $15(8)$ \\
\hline Water bucket (20 L) & $19(8)$ & $19(5)$ & $26(12)$ & $26(9)$ & $40(5)$ & $40(3)$ & $85(25)$ & $85(17)$ \\
\hline Water bottle (12 L) & $9(4)$ & $9(4)$ & $5(0)$ & $5(0)$ & $2(0)$ & $2(0)$ & $16(4)$ & $16(4)$ \\
\hline Others & $17(15)$ & $17(7)$ & $11(4)$ & $11(3)$ & $12(7)$ & $12(7)$ & $40(26)$ & $40(17)$ \\
\hline Total & $123(90)$ & $123(56)$ & $81(46)$ & $81(43)$ & $129(65)$ & $129(61)$ & $333(201)$ & $333(160)$ \\
\hline
\end{tabular}




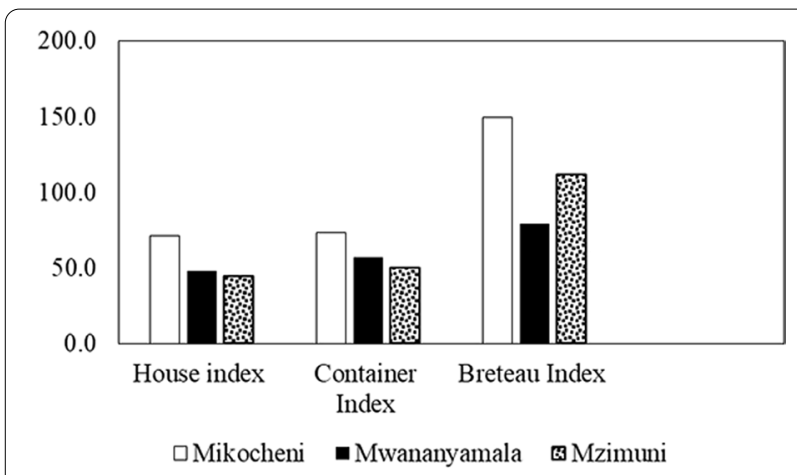

Fig. 2 House, Container and Breteau indices by ward

from emerged pupae. All the mosquito pools tested negative for DENV (Fig. 3).

\section{Discussion}

Although dengue virus was not detected from mosquitoes, Aedes mosquito abundance and larvae indices were high in Kinondoni district. Ae. aegypti accounted for less than one-fourth of the adult female mosquitoes collected. The majority of Ae. aegypti were collected from Mikocheni ward. Similar findings were previously reported in Dar es Salaam [8, 31]. In comparison, Mboera et al. found five mosquito species in the same district in a study conducted during the dengue outbreak of 2014/2015 [8]. The study by Mboera et al. was conducted during the long rainy season (April-May) [8], compared with this study that was carried out during the end of a short rainy season (December) and the beginning of the dry season (January). The effect of seasonal variations on the abundance and distribution of Aedes mosquitoes has been reported by other authors [32,33].

Results from house survey show that three-quarters of the houses in Kinondoni had water-holding containers that were potential breeding sites of Aedes mosquitoes. More than half of the inspected houses had water-holding containers infested with Aedes mosquito larvae and or pupae. The overall house index in our study was lower than that previously reported in the same district [8], most likely due to the seasonal differences. Results from a study in northern Ghana also showed higher house indices ranging from $55.9 \%$ to $88.3 \%$ [34]. The overall container index in the current study was higher than previously reported [8]. The findings from another study in the rural Ifakara district of south-eastern Tanzania revealed relatively lower larvae indices than those found in this study [35]. High Aedes mosquito indices reported in this study were not surprising as the study was carried out during the end of the short rainy and the start of the dry season [25]. The high Breteau index reported in this study indicates that the residents of Kinondoni are likely to be at high risk of dengue virus transmission [36]. These findings agree with the results reported from a study in northern Ghana, where Breteau indices of 72.4 to 180.9 were reported during a dry season [34]. The higher larval indices observed in Mikocheni compared to the other wards could be explained by several factors, including fact that Mikocheni is high-income ward characterized by houses with large and shaded peridomestic environments (gardens) with potted flowers, which are potential mosquito breeding habitats. These observations call for the need to improve Aedes mosquito control practices in the study district to reduce the risk of DENV transmission.

In the house survey, it was found that the most common breeding containers for the Aedes mosquitoes were discarded car tires and flower pots. It is a presumption that a large number of water-holding containers with immature mosquito stages found outdoors in Kinondoni could be a reason for the abundance of Ae. aegypti reported in this study. Similarly, a previous study found that water-holding containers left outdoors were harbouring Aedes immature stages in Kinondoni and other districts of Dar es Salaam [8]. Ae. aegypti has also been reported as a common outdoor breeding mosquito in the rural areas of Tanzania [35]. The shortage of water supply may have led to many households keeping containers for water storage in their houses. Furthermore, the flower pots that retain water and improper disposal of used tires are likely to provide suitable sites for Aedes mosquito breeding. These factors probably contributed to the high number of breeding sites that favoured high

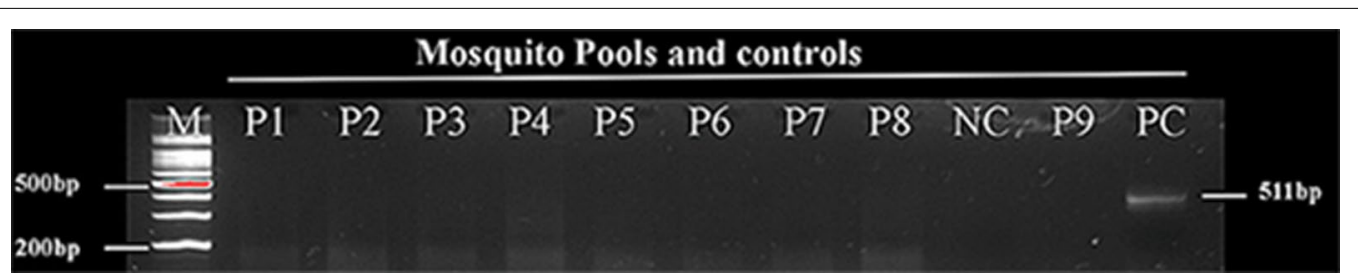

Fig. 3 Agarose gel electrophoresis image of RT-PCR test results for dengue virus in female Ae. aegypti mosquitoes. M is a 100 bp DNA ladder, P1-9 are representative of mosquito pools tested (samples), $\mathrm{PC}$ - positive control and NC — negative control 
Aedes abundance [37]. Highly pupae productive containers were observed to be discarded car tires, cement water tanks and flower pots. Although all the water-holding containers were found to have pupae, mosquito control measures targeting breeding habitats should be directed to water-holding containers perceived to hold water for longer periods. Similar observations were reported from other studies in Dar es Salaam, Tanzania $[8,38]$ and Mombasa Kenya [35, 36].

Laboratory analysis showed that DENV was not detected in the mosquito pools tested. In contrary, a previous study in Dar es Salaam reported an infection rate of $6.8 \%$ [8]. The absence of DENV infection in Aedes mosquitoes has also been reported in a study in Kenya [39]. The absence of infection could be due to several factors, including lower average precipitation [40], number of mosquitoes tested, high ratio of hatched mosquitoes compared to the total number of mosquitoes tested and the absence of DENV circulating in humans during the study period [39]. Although DENV was not detected in Aedes mosquitoes, their abundance and the large proportion of water-holding containers infested indicate the risk of DENV transmission in the study areas is high. A recent study reported Kinondoni district to have the highest seroprevalence of dengue than elsewhere in Tanzania [16].

\section{Conclusion}

This study reveals the presence and abundant Ae. aegypti mosquitoes and a large proportion of water-holding containers infested with larvae and pupae in Kinondoni district, Tanzania, suggesting that residents of the district are at higher risk of DENV transmission. Although DENV was not detected, our findings emphasize the need for continuous mosquito vector surveillance in Tanzania to guide strategies for appropriate vector control to prevent the possibility of future DENV outbreaks.

\section{Limitation of the study}

The few numbers of adult, trap collected female $A e$. aegypti mosquitoes observed in this study may be due to sampling period of the year which is the start of dry season. In this study, the virus detection rate is also considered to be low because of the high ratio of hatched mosquitoes compared to the total number of mosquitoes tested. This was a cross-sectional study and hence its findings cannot be used to interpret the seasonal abundance of the mosquito.

\section{Abbreviations}

DENV: Dengue virus; RT-PCR: Reverse transcription-polymerase chain reaction; Cl: Container index; HI: House index; Bl: Breteau index.

\section{Acknowledgements}

We are thankful to Mr. John Fundi of National Institute for Medical Research, Amani Research Centre and Mr. Nicodem Kihiyo of Muhimbili University of Health and Allied Sciences for their excellent technical assistance in entomology.

\section{Authors' contributions}

BLN conceived the idea for the study; LEGM, IM and MM designed and coordinated field data collection. BLN, MM, IM, GOM and MRM performed molecular analyses. BLN and GOM performed the statistical analysis. BLN, LEGM, AC, GOM and SR finalized the manuscript based on the comments from other authors. All authors read and approved the final manuscript.

\section{Funding}

This study was funded by the Government of the United Republic of Tanzania through the World Bank (IDA credit 5799-TZ) to the SACIDS Africa Centre of Excellence for Infectious Diseases of Humans and Animals in East and Southern Africa of the SACIDS Foundation for One Health at the Sokoine University of Agriculture.

\section{Availability of data and materials}

The data sets used and/or analysed during the current study are available from the corresponding

author upon request.

\section{Declarations}

\section{Ethics approval and consent to participate}

This study was approved by the Medical Research Coordinating Committee of the National Institute for Medical Research in Tanzania (NIMR/HQ/P.12 VOL XXXII/37). Permissions to access household premises were sought from the respective heads of household.

\section{Consent for publication}

Not applicable.

\section{Competing interests}

The authors declare that there are no competing interests.

\section{Author details}

${ }^{1}$ Department of Veterinary Microbiology, Parasitology and Biotechnology, Sokoine University of Agriculture, Morogoro, Tanzania. ${ }^{2}$ SACIDS Foundation for One Health, Sokoine University of Agriculture, Morogoro, Tanzania. ${ }^{3}$ Faculty of Natural and Applied Sciences, St John's University of Tanzania, Dodoma, Tanzania. ${ }^{4}$ Department of Medical Sciences and Technology, Mbeya University of Science and Technology, Mbeya, Tanzania. ${ }^{5}$ Department of Microbiology and Immunology, Muhimbili University of Health and Allied Sciences, Dar es Salaam, Tanzania.

Received: 19 August 2021 Accepted: 27 December 2021

Published online: 04 January 2022

\section{References}

1. Messina JP, Brady OJ, Golding N, Kraemer MUG, Wint GRW, Ray SE, et al. The current and future global distribution and population at risk of dengue. Nat Microbiol. 2019;4(9):1508-15.

2. WHO. Global Strategy for Dengue Prevention and Control 2012-2020 [Internet]. World Health Organiszation. World Health Organization; 2012 43 p. Available from: http://scholar.google.com/scholar?hl=en\&btnG= Search\&q=intitle:Global+strategy+for+dengue+prevention+and+ control\#8

3. Zambrano LI, Sevilla C, Reyes-García SZ, Sierra M, Kafati R, RodriguezMorales AJ, et al. Potential impacts of climate variability on Dengue Hemorrhagic Fever in Honduras, 2010. Trop Biomed. 2012;29(4):499-507.

4. Christie T. Remarks on -'kidinga pepo": a peculiar form of exan-thematous disease. Br Med J. 1872;1(596):577-9.

5. Gubler DJ. Dengue and dengue hemorrhagic fever. Semin Pediatr Infect Dis. 1997;8(1):3-9. 
6. Halstead SB. Dengue virus-mosquito interactions. Annu Rev Entomol. 2008;53(1):273-91.

7. Amarasinghe A. Dengue Virus Infection in Africa. Emerg Infect Dis. 2011; http://wwwnc.cdc.gov/eid/article/17/8/10-1515_article.htm. Accessed 15 Nov 2021

8. Mboera LEG, Mweya CN, Rumisha SF, Tungu PK, Stanley G, Makange MR et al. The risk of dengue virus transmission in Dar es Salaam, Tanzania during an epidemic period of 2014. PLoS Negl Trop Dis. 2016;10:1.

9. Okada K, Morita R, Egawa K, Hirai Y, Kaida A, Shirano M, et al. Dengue virus type 1 infection in traveler returning from Tanzania to Japan, 2019. Emerg Infect Dis. 2019;25(9):1782-4.

10. Vairo F, Mboera LEG, de Nardo P, Oriyo NM, Meschi S, Rumisha SF, et al. Clinical, virologic, and epidemiologic characteristics of dengue outbreak, Dar es Salaam, Tanzania, 2014. Emerg Infect Dis. 2016;22(5):895-9.

11. WHO Regional Office for Africa. Weekly Bulletin on Outbreaks. 2020; (August):1-20.

12. Chipwaza B, Mugasa JP, Selemani M, Amuri M, Mosha F, Ngatunga SD, et al. Dengue and Chikungunya Fever among Viral Diseases in Outpatient Febrile Children in Kilosa District Hospital Tanzania. PLoS NegI Trop Dis. 2014;8:11.

13. Kajeguka DC, Kaaya RD, Mwakalinga S, Ndossi R, Ndaro A, Chilongola JO, et al. Prevalence of dengue and chikungunya virus infections in northeastern Tanzania: a cross sectional study among participants presenting with malaria-like symptoms. BMC Infect Dis. 2016;16(1):1-9.

14. Vairo F, Nicastri E, Yussuf SM, Cannas A, Meschi S, Mahmoud MAA, et al. $\operatorname{lgG}$ against dengue virus in healthy blood donors, Zanzibar Tanzania. Emerg Infect Dis. 2014;20(3):465-8.

15. Ward T, Samuel M, Maoz D, Runge-Ranzinger S, Boyce R, Toledo J, et al. Dengue data and surveillance in Tanzania: a systematic literature review. Trop Med Int Health. 2017;22(8):960-70.

16. Mwanyika GO, Sindato C, Rugarabamu S, Rumisha SF, Karimuribo ED, Misinzo G, et al. Seroprevalence and associated risk factors of chikungunya, dengue, and Zika in eight districts in Tanzania. Int J Infect Dis. 2021;111:271-80

17. Chipwaza B, Sumaye RD, Weisser M, Gingo W, Yeo NKW, Amrun SN, et al. Occurrence of 4 dengue virus serotypes and chikungunya virus in Kilombero valley, Tanzania, during the Dengue outbreak in 2018. Open Forum Infect Dis. 2021;8(1):1-6.

18. Mwanyika GO, Mboera LEG, Rugarabamu S, Makange M, Sindato C, Lutwama JJ, et al. Circulation of dengue serotype 1 viruses during the 2019 outbreak in Dar es Salaam Tanzania. Pathog Glob Health. 2021;00(00):1-9.

19. Mathias L, Baraka V, Philbert A, Innocent E, Francis F, Nkwengulila G, et al, Habitat productivity and pyrethroid susceptibility status of Aedes aegypti mosquitoes in Dar es Salaam Tanzania. Infect Dis Poverty. 2017:6(1):1-10.

20. Paupy C, Delatte H, Bagny L, Corbel V, Fontenille D. Aedes albopictus, an arbovirus vector: from the darkness to the light. Microbes Infect. 2009;11(14-15):1177-85.

21. Delatte H, Desvars A, Bouétard A, Bord S, Gimonneau G, Vourch G, et al. Blood-feeding behavior of Aedes albopictus, a vector of chikungunya on la réunion. Vector-Borne Zoonotic Dis. 2010;10(3):249-58.

22. Philbert A, Msonga A. Dengue vector distribution and their infection status in selected regions in Tanzania. Tanzan J Sci. 2020;46(3):636-46.

23. Bisimwa P, Angwenyi S, Weyer J, Patrick BN, Kinimi E, Shayo MJ, et al. Distribution and diversity of mosquitoes and the role of Aedes in the transmission of arboviruses in selected districts of Tanzania. Int J Mosa Res. 2018;5(1):53-60.

24. NBS. National Bureau of Statistics - 2012 PHC: Population Distribution by Administrative Areas. 2012. https://www.nbs.go.tz/index.php/en/censussurveys/population-and-housing-census/162-2012-phc-population-distr ibution-by-administrative-areas

25. Ndetto EL, Matzarakis A. Basic analysis of climate and urban bioclimate of Dar es Salaam Tanzania. Theor Appl Climatol. 2013;114(1-2):213-26.

26. Reinert JF, Harbach RE, Kitching IJ. Phylogeny and classification of Aedini (Diptera: Culicidae), based on morphological characters of all life stages. Zool J Linn Soc. 2004;142(3):289-368.

27. Ngugi HN, Mutuku FM, Ndenga BA, Musunzaji PS, Mbakaya JO, Aswani $P$, et al. Characterization and productivity profiles of Aedes aegypti (L.) breeding habitats across rural and urban landscapes in western and coastal Kenya. Parasit Vectors. 2017;10(1):331-331.

28. WHO. Operational guide for assessing the productivity of Aedes aegypti breeding sites. WHO. World Health Organization; 2011 [cited 2021 Nov
8]. https://www.who.int/tdr/publications/tdr-research-publications/soppupal-surveys/en/

29. Lanciotti RS, Calisher CH, Gubler DJ, Chang GJ, Vorndam AV. Rapid detection and typing of dengue viruses from clinical samples by using reverse transcriptase-polymerase chain reaction. J Clin Microbiol. 1992;30(3):545-51.

30. WHO. Technical guide for a system of yellow fever surveillance. Wkly Epidemiol Rec. 1971;46(49):493-500.

31. Govella NJ, Chaki PP, Mpangile JM, Killeen GF. Monitoring mosquitoes in urban Dar es Salaam: Evaluation of resting boxes, window exit traps, CDC light traps, Ifakara tent traps and human landing catches. Parasit Vectors. 2011;4(1):40-40.

32. Vezzani D, Velázquez SM, Schweigmann N. Seasonal pattern of abundance of Aedes aegypti (Diptera: Culicidae) in Buenos Aires City Argentina. Mem Inst Oswaldo Cruz. 2004;99(4):351-6.

33. Wongkoon S, Jaroensutasinee M, Jaroensutasinee K. Distribution, seasonal variation \& dengue transmission prediction in Sisaket Thailand Indian J Med Res. 2013;138(3):347-53.

34. Appawu M, Dadzie S, Abdul H, Asmah H, Boakye D, Wilson M, et al. Surveillance of viral haemorrhagic fevers in Ghana: entomological assessment of the risk of transmission in the northern regions Ghana. Med J. 2010:40:3.

35. Kahamba NF, Limwagu AJ, Mapua SA, Msugupakulya BJ, Msaky DS, Kaindoa EW, et al. Habitat characteristics and insecticide susceptibility of Aedes aegypti in the Ifakara area, south-eastern Tanzania. Parasit Vectors. 2020;13(1):1-15.

36. Sanchez L, Vanlerberghe V, Alfonso L, Marquetti MDC, Guzman MG, Bisset $J$, et al. Aedes aegypti larval indices and risk for dengue epidemics. Emerg Infect Dis. 2006;12(5):800-6.

37. Eberendu IF, Ozims SJ, Agu GC, Amah HC, Obasi CC, Obioma-Elemba $\mathrm{JE}$, et al. Impact of human activities on the breeding of mosquitoes of human disease in Owerri metropolis, Imo state. Int J Adv Res Biol Sci IJARBS. 2017:4(12):98-106.

38. Msellemu D, Gavana T, Ngonyani H, Mlacha YP, Chaki P, Moore SJ. Knowledge, attitudes and bite prevention practices and estimation of productivity of vector breeding sites using a habitat suitability score (Hss) among households with confirmed dengue in the 2014 outbreak in dar es salaam, tanzania. PLoS Negl Trop Dis. 2020;14(7):1-18.

39. Iwashita H, Higa Y, Futami K, Lutiali PA, Njenga SM, Nabeshima T, et al. Mosquito arbovirus survey in selected areas of Kenya: detection of insectspecific virus. Trop Med Health. 2018;46(1):1-15.

40. Olson MF, Juarez JG, Kraemer MUG, Messina JP, Hamer GL. Global patterns of aegyptism without arbovirus. PLoS Negl Trop Dis. 2021;15(5):1-12.

\section{Publisher's Note}

Springer Nature remains neutral with regard to jurisdictional claims in published maps and institutional affiliations.

Ready to submit your research? Choose BMC and benefit from:

- fast, convenient online submission

- thorough peer review by experienced researchers in your field

- rapid publication on acceptance

- support for research data, including large and complex data types

- gold Open Access which fosters wider collaboration and increased citations

- maximum visibility for your research: over $100 \mathrm{M}$ website views per year

At BMC, research is always in progress.

Learn more biomedcentral.com/submissions 